\title{
Instructions to Reviewers
}

Thank-you for agreeing to act as a reviewer for the Security Protocols Workshop. Please follow these five (5) simple steps:

1. Send your position paper to the person whose name appears at the top of the list below.

2. Remove the first name on the list and add your own name and address at the bottom.

3. Make sixteen (16) copies of the resulting letter.

4. Choose the sixteen (16) people whom you believe should be invited to submit position papers to the workshop, and send them each one copy.

5. Within a month, you should receive approximately 65,536 position papers to review, at least some of which are bound to be crackers.

DO NOT BREAK THE CHAIN. One reviewer did, and ended up reviewing his own submission by mistake. He rejected it!

6. Please complete all your reviews by Feb 15 .

Best wishes,

Bruce Christianson

Bruno Crispo

James Malcolm

Michael Roe 